\title{
Brain-Derived Neurotrophic Factor Has a Transsynaptic Trophic Effect on Neural Activity in an Adult Forebrain Circuit
}

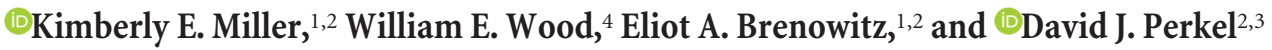 \\ Departments of ${ }^{1}$ Psychology, ${ }^{2}$ Biology, ${ }^{3}$ Otolaryngology, and ${ }^{4}$ Neuroscience Graduate Program, University of Washington, Seattle, Washington \\ 98195-1800
}

While hormone-driven plasticity in the adult brain is well studied, the underlying cellular and molecular mechanisms are less well understood. One example of this is seasonal plasticity in the avian brain, where song nuclei exhibit hormonally driven changes in response to changing photoperiod and circulating sex steroid hormones. Hormone receptor activation in song nucleus HVC (proper name) elicits a robust change in activity in target nucleus RA (robust nucleus of the arcopallium), but the molecular signal responsible for this is unknown. This study addressed whether brain-derived neurotrophic factor (BDNF) mediates a transsynaptic effect from HVC to RA in male Gambel's white-crowned sparrows (Zonotrichia leucophrys gambelii). In situ hybridization confirmed an increase in BDNF expression in HVC neurons of birds switched to a long-day (LD) photoperiod plus systemically elevated testosterone (T) levels, compared with short-day (SD) conditions. BDNF expression was virtually absent in RA neurons of SD birds, increasing to barely detectable levels in a small subset of cells in $\mathrm{LD}+\mathrm{T}$ birds. Infusion of BDNF protein adjacent to the RA of SD birds caused an increase in the spontaneous neuron firing rate. Conversely, the infusion of ANA12, a specific antagonist of the tyrosine-related kinase B (TrkB) for BDNF, prevented the increase in RA neuron firing rate in $\mathrm{LD}+\mathrm{T}$ birds. These results indicate that BDNF is sufficient, and TrkB receptor activation is necessary, for the transsynaptic trophic effect exerted by HVC on RA. The dramatic change in the activity of RA neurons during the breeding season provides a clear example of transsynaptic BDNF effects in the adult brain in a functionally relevant circuit.

Key words: breeding condition; neurotrophin; seasonal; songbird; steroid; transsynaptic

\section{Significance Statement}

Sex steroid hormones drive changes in brain circuits in all vertebrates, both within specific neurons and on their synaptic targets. Such changes can lead to profound changes in behavior, but little is known about the precise molecular mechanisms that underlie this process. We addressed this question in a seasonally breeding songbird and found that the trophic effects of one forebrain song nucleus on its target are mediated transsynaptically by the neurotrophin BDNF. This suggests that, in addition to their role in development, neurotrophins have critical roles in adult brain plasticity.

\section{Introduction}

Steroid sex hormones have trophic effects on brain structures and associated behaviors across vertebrates (Brenowitz, 2013). One mechanism of steroid action in the brain is via increased expres-

Received Sept. 30, 2019; revised Dec. 2, 2019; accepted Dec. 11, 2019.

Author contributions: K.E.M., W.E.W., E.A.B., and D.J.P. designed research; K.E.M., W.E.W., and D.J.P. performed research; K.E.M. and W.E.W. analyzed data; K.E.M., W.E.W., E.A.B., and D.J.P. wrote the paper.

This work was supported by National Institutes of Health Grants R01-MH-053032 to E.A.B. and R01-NS-103973 to

E.A.B. and D.J.P. We thank Regeneron for the gift of BDNF.

The authors declare no competing financial interests.

Correspondence should be addressed to David J. Perkel at perkel@uw.edu.

W.E. Wood's present address: Helen Willis Neuroscience Institute, University of California, Berkeley, Berkeley, CA 94720.

https://doi.org/10.1523/JNEUROSCI.2375-19.2019

Copyright $\odot 2020$ the authors sion of trophic proteins. Songbirds show dramatic seasonal changes in brain circuitry and behavior caused by sex steroids. The springtime increase in day length raises circulating testosterone $(\mathrm{T})$ levels in males. $\mathrm{T}$ acts on the brain to increase song production and improve song quality. This transition into breeding condition can be reproduced in the laboratory by housing birds in long-day (LD) conditions and raising T via a subcutaneous implant.

The descending forebrain song motor pathway changes in response to increased T levels. In adult male Gambel's white-crowned sparrows (GWCSs; Zonotrichia leucophrys gambellii), the premotor song nucleus HVC (proper name) grows primarily due to adult neurogenesis (Tramontin et al., 1998; Brenowitz, 2015). $\mathrm{LD}+\mathrm{T}$ increases the differentiation and survival of new neurons in HVC, and growth of new axons to nucleus RA (robust nucleus 
of the arcopallium; Nottebohm et al., 1987; Kirn and DeVoogd, 1989). RA neurons shows increased neuronal soma size, dendritic spine density (for review, see Brenowitz, 2008), spontaneous firing (Park et al., 2005; Meitzen et al., 2007a), and intrinsic excitability (Meitzen et al., 2009a). RA grows without the addition of new neurons.

HVC mediates the trophic effects of $\mathrm{LD}+\mathrm{T}$ on RA transsynaptically. HVC lesions or blockade of androgen receptors (ARs) and estrogen receptors (ERs) in HVC prevent the growth and increased spontaneous activity of RA neurons (Brenowitz and Lent, 2001; Meitzen et al., 2007b). Local coactivation of AR and ER in HVC is sufficient to induce growth and increased firing in RA in birds maintained on short days (SDs). Hormone infusion directly onto RA, however, does not increase neuron size or firing rate (Meitzen et al., 2007b).

Brain-derived neurotrophic factor (BDNF) could mediate this effect (Akutagawa and Konishi, 1998; Dittrich et al., 1999; Wissman and Brenowitz, 2009; Thompson et al., 2012; Brenowitz, 2013; Tang and Wade, 2016). BDNF is upregulated in HVC neurons of LD $+\mathrm{T}$ birds (Wissman and Brenowitz, 2009; Thompson et al., 2012). Isotope-based in situ hybridization (ISH) detected low levels of BDNF mRNA in RA and no significant change in $\mathrm{LD}+\mathrm{T}$ (Wissman and Brenowitz, 2009). However, cDNA microarray analysis of tissue punches from RA showed an upregulation of BDNF expression after LD $+\mathrm{T}$ (Thompson et al., 2012), but these changes could arise from non-neuronal cells (Jean et al., 2008; Béjot et al., 2011; Chen et al., 2013). The tyrosine-related kinase B (TrkB) for BDNF, is present in RA neurons (Johnson et al., 1997; Dittrich et al., 1999; Wissman and Brenowitz, 2009).

BDNF has trophic effects on HVC and RA in juvenile finches (Dittrich et al., 1999). In SD adult GWCSs, BDNF infusion into RA increases soma size (Wissman and Brenowitz, 2009). Moreover, the infusion of TrkB-Fc (Fc domain of human IgG), a BDNFbinding antibody fragment, prevents RA growth following $\mathrm{LD}+\mathrm{T}$ treatment.

In mammals, BDNF is involved in neuronal survival, axonal and dendritic outgrowth, synaptic plasticity, and the regulation of electrical properties (Leal et al., 2014; Kowiański et al., 2018). These actions may depend on whether BDNF signaling is transient or sustained (Ji et al., 2010; Guo et al., 2018). A transsynaptic effect of BDNF has been reported in cortical neurons in acute slices and in slice or dissociated neuronal cultures (Zhou and Rush, 1996; Altar et al., 1997; Conner et al., 1997; Kohara et al., 2001, 2003). Hormone-induced changes in RA, including dendritic branching and growth of new dendritic spines, take up to 3 weeks to complete (Meitzen et al., 2007b), suggesting a sustained mode of action.

We hypothesized that BDNF mediates the HVC-driven transsynaptic changes in RA spontaneous activity in GWCSs. We used ISH to measure BDNF expression. We asked whether the infusion of exogenous BDNF onto RA is sufficient to increase RA neuron firing rate in nonbreeding birds. We also tested whether TrkB activation in RA is necessary for increased spontaneous activity following $\mathrm{LD}+\mathrm{T}$.

\section{Materials and Methods}

Animals. Male GWCSs collected in eastern Washington during their autumn migration were used for this study. Sparrows were group housed in outdoor aviaries for up to 12 weeks before being placed in indoor aviaries under controlled SD light conditions (nonbreeding, SD, 8 h light, no supplemental T) for a minimum of 10 weeks to ensure they had basal $\mathrm{T}$ levels, low spontaneous firing rates in RA, and variable song structure, typical of nonbreeding season conditions (Smith et al., 1995; Tramontin et al., 2000; Park et al., 2005; Meitzen et al., 2007a,b). All birds had ad libitum access to food and water throughout experiments, and all procedures were approved by the Institutional Animal Care and Use Committee at the University of Washington.

Hormone manipulation and measurement. Blood samples were collected from the alar vein in the wing from all birds before photoperiod and hormone manipulations. Some birds were implanted subcutaneously above the scapula with a $9 \mathrm{~mm}$ SILASTIC capsule $(1.47 \mathrm{~mm}$ inner diameter, $1.96 \mathrm{~mm}$ outer diameter) filled with crystalline $\mathrm{T}$ (SigmaAldrich) and transferred to an LD photoperiod for $14 \mathrm{~d}$ to allow breeding-like growth of the song nuclei (breeding, LD+T, $20 \mathrm{~h}$ of light; Tramontin et al., 2000).

Other birds were kept on SD conditions with no T implant throughout the experiment to mimic the nonbreeding condition. Blood samples were taken again immediately before birds were killed, and all samples were assayed to verify the breeding condition using a testosterone ELISA kit (catalog \#ADI 065-009, Enzo Life Sciences).

In situ hybridization. For ISH analysis of BDNF expression in HVC and $\mathrm{RA}, \mathrm{LD}+\mathrm{T}(14 \mathrm{~d}, n=5)$ and SD $(n=3)$ birds were anesthetized with isoflurane and decapitated to rapidly remove and freeze the brain. The brain was embedded in tissue freezing medium (Tissue-Tek O.T.C. Compound, Sakura FineTek USA) and frozen in 2-methylpentane chilled with dry ice. Parasagittal sections (20 $\mu \mathrm{m}$ thick) were cut with a cryostat (Reichert-Jung), collected onto Superfrost Plus Microscope Slides, and stored at $-80^{\circ} \mathrm{C}$ until staining. Sections were fixed in $4 \%$ paraformaldehyde in $0.1 \mathrm{M}$ phosphate buffer, treated to quench endogenous peroxidase, and permeabilized with RNAscope protease IV (Advanced Cell Diagnostics) before incubation in a specially designed probe targeting portions of the region spanning residues 22-717 of the cDNA sequence for BDNF in Zonotrichia leucophrys gambelii (accession \#XM_026796600.1; RNAscope Probe-Zle-BDNF, catalog \#468341, Advanced Cell Diagnostics) at $40^{\circ} \mathrm{C}$ for $2 \mathrm{~h}$. The accession number represents the NCBI sequence for BDNF in the congeneric white-throated sparrow, Zonotrichia albicollis, but our own sequence data from GWCSs shows $100 \%$ sequence identity in this region of the BDNF gene between Z. albicollis and GWCSs (R. Luche, K. Lent, K. Miller, E. Brenowitz, unpublished observations). Sections were rinsed and additional scaffolding steps (RNAscope Probe, catalog \#322300, Advanced Cell Diagnostics) were applied to enhance the signal before DAB staining. All sections were reacted in parallel in a single run to minimize staining variability.

Slides were thionin stained, dehydrated, and coverslipped for examination on a Leica DMR Microscope equipped with a DC350F color camera. Images were collected and analyzed using ImageJ (Schneider et al., 2012). In sections of HVC and RA spaced $100 \mu \mathrm{m}$ apart, fields for semiquantitative analysis were selected using a customized random, systematic sampling protocol that yields estimates that do not differ from stereological methods (Tramontin et al., 1998). The quantification of neurons was performed according to the quickscore method (Detre et al., 1995). Neurons were identified by Nissl staining, and individual riboprobe dots within each neuron were summed and categorized into the following groups: group 0 ( 0 dots/cell); group 1 (1-3 dots/cell); group 2 (4-9 dots/cell); group 3 (10-15 dots/cell); and group 4 (>15 dots/cell). From this, the H-score was calculated per nucleus/animal using the following formula:

$$
\begin{aligned}
\text { H score }=(\text { fraction of neurons in group } 0 * 0) & \\
& +\left(\text { fraction of neurons in group } 1^{\star} 1\right) \\
& +(\text { fraction of neurons in group } 2 * 2) \\
& +(\text { fraction of neurons in group } 3 * 3) \\
& +(\text { fraction of neurons in group } 4 * 4)
\end{aligned}
$$

Cannulation and drug infusion. Birds were anesthetized with isoflurane and placed into the stereotaxic apparatus (Kopf Instruments) for surgery. We lowered a cannula near RA ( $3.4 \mathrm{~mm}$ lateral, $1.25 \mathrm{~mm}$ posterior to the intersection of the midsagittal and transverse sinuses; depth $=0.8 \mathrm{~mm}$ ). Histological analysis demonstrated that the ends of the cannula track 
were $281 \pm 24 \mu \mathrm{m}$ dorsolateral to RA and did not damage the HVC-RA fiber tract. We fixed the cannula to the skull with dental cement and attached it via polyethylene tubing (inner diameter, $0.76 \mathrm{~mm}$ ) to an osmotic minipump (model 1002D, Alzet Durect). Pumps were filled with sterile saline and placed in Eppendorf tubes containing saline. Tubes were held against the back of the bird in customized "backpacks," as described previously (Meitzen et al., 2007b).

After $7 \mathrm{~d}$, the saline pumps were exchanged for drug infusion pumps. SD birds were given infusions of recombinant BDNF protein $(30 \mu \mathrm{g} / \mathrm{ml}$; Regeneron), cytochrome $c$ (CytC; $30 \mu \mathrm{g} / \mathrm{ml}$; Sigma-Aldrich) used as a protein control of similar molecular weight (Galuske et al., 2000; Tropea et al., 2003), or saline as an infusion control. All proteins were dissolved in saline. $\mathrm{LD}+\mathrm{T}$ birds were given infusions of the specific TrkB antagonist ANA-12 (30 $\mu \mathrm{g} / \mathrm{ml}$; Sigma-Aldrich) in saline (Cazorla et al., 2011). They were implanted with a Silastic T pellet and switched to LD for $14 \mathrm{~d}$. Tetramethylrhodamine isothiocyanate (TRITC) was included in each pump to identify the location and spread of the infusion. Sections that did not show clear dye infusion in the arcopallium (visualized during vibratome slicing) were not used for analysis. Following recordings (below), brain slices were postfixed in $4 \%$ paraformaldehyde plus $25 \%$ sucrose for at least $24 \mathrm{~h}$ before resectioning at $40 \mu \mathrm{m}$ with a freezing microtome (American Optical). Sections were then mounted onto slides, dried, thionin stained, and coverslipped with DPX (Electron Microscopy Sciences). We then measured the distance from the end of the cannula track to RA.

Electrophysiology. Fourteen days after the beginning of drug infusion, birds were briefly anesthetized with isoflurane and decapitated. The brain was rapidly removed to ice-cold oxygenated ACSF containing the following (in mM): $119 \mathrm{NaCl}, 2.5 \mathrm{KCl}, 1.3 \mathrm{MgSO}_{4}, 2.5 \mathrm{CaCl}_{2}, 1 \mathrm{NaH}_{2} \mathrm{PO}_{4}$, 16.2 $\mathrm{NaHCO}_{3}, 11$ D-glucose, and 10 HEPES. Parasagittal brain slices $(250$ or $300 \mu \mathrm{m}$ thick) were prepared with a vibrating microtome (Vibratome, Leica Biosystems) and placed into room temperature oxygenated ACSF (HEPES replaced with equiosmolar $\mathrm{NaHCO}_{3}$ ) for $1 \mathrm{~h}$ before recording. In all birds, TRITC was found inside RA.

All recordings were made with tissue submerged in an oxygenated ACSF containing the ionotropic glutamate receptor antagonist \& kynurenic acid (KA) and the $\mathrm{GABA}_{\mathrm{A}}$ receptor antagonist picrotoxin (PTX; in mM) 119 $\mathrm{NaCl}, 2.5 \mathrm{KCl}, 1.3 \mathrm{MgSO}_{4}, 2.5 \mathrm{CaCl}_{2}, 1 \mathrm{NaH}_{2} \mathrm{PO}_{4}, 16.2 \mathrm{NaHCO}_{3}, 11$ D-glucose, and $10 \mathrm{NaHCO}_{3}, 1 \mathrm{KA}, 0.15$ picrotoxin) kept at $29-31^{\circ} \mathrm{C}$. The addition of KA and PTX allowed the measurement of intrinsic spontaneous activity, independent of synaptic inputs. All ACSF and KA/PTX solutions were adjusted to $300 \pm 5 \mathrm{mOsm}$ with sucrose.

Extracellular recordings were made with glass electrodes filled with ACSF (resistance, 5-8 M $\Omega$ ). Voltage signals from neurons encountered within RA were amplified using an Axoclamp 2B or Multiclamp 700B amplifier (Molecular Devices), bandpass filtered (3 Hz to $10 \mathrm{kHz}$ ), and amplified further with a Brownlee Precision model 410 amplifier. Signals were digitized at $20 \mathrm{kHz}$ via a Molecular Devices Digidata 1322 digitizer and recorded using pClamp 9 or 10 software (Molecular Devices). Stable recordings were made for $2-5 \mathrm{~min}$. Action potentials were detected using Spike 2.5 (Cambridge Electronic Design) or pClamp software using simple threshold-based spike detection since all recordings had a $>3: 1$ signal-to-noise ratio, and the firing rate was calculated as the number of action potentials detected divided by the duration of the recording.

Experimental design. This was a cohort study in which birds were treated with different conditions $(\mathrm{SD}, \mathrm{LD}+\mathrm{T}, \mathrm{SD}+\mathrm{BDNF}, \mathrm{SD}+\mathrm{CytC}$, $\mathrm{LD}+\mathrm{T}+\mathrm{Ana12}$ ), and neuronal firing was measured in brain slices from each bird.

Statistical analyses. Statistical analysis was performed with Prism (GraphPad Software). Unless otherwise specified, multigroup comparisons were made using a nested ANOVA, allowing the inclusion of data from multiple neurons in each animal, while keeping the main sample size as the individual bird.

\section{Results}

Hormone levels

Fourteen days after the start of hormone manipulations, T measured from blood plasma was significantly higher in $\mathrm{LD}+\mathrm{T}$ birds $($ mean \pm SEM, $17.2 \pm 3.7 \mathrm{ng} / \mathrm{ml})$ than in SD birds $(0.37 \pm 0.09$

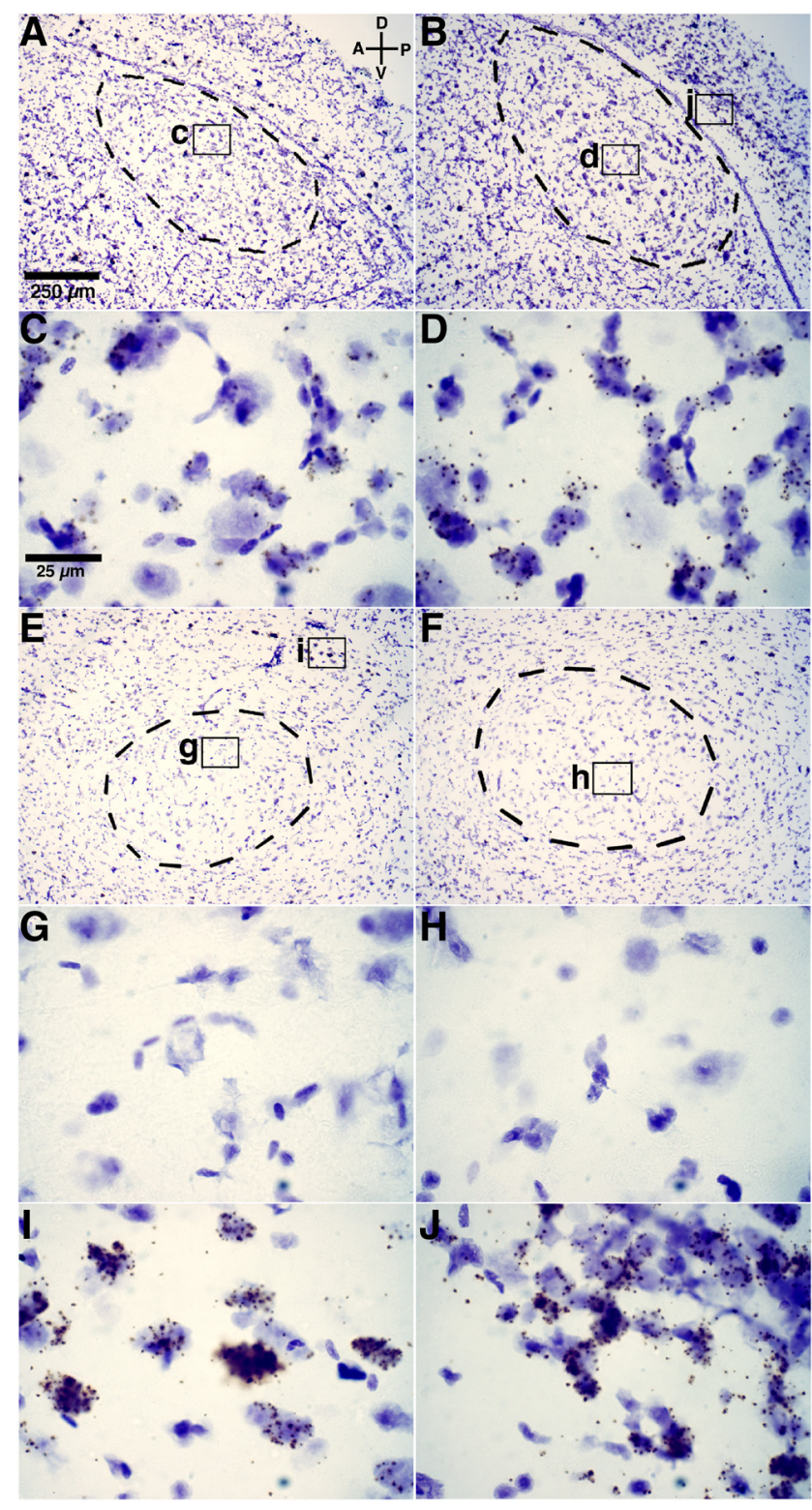

Figure 1. BDNF mRNA expression increases in LD HVC but remains sparse in RA. $\boldsymbol{A}, \boldsymbol{B}, \mathrm{Low}$ magnification images of SD and LD + THVC illustrate the distribution of the probe label in and surrounding HVC. $C, D$, High-magnification images from boxes of corresponding SD and LD +T HVC. $\boldsymbol{E}, \boldsymbol{F}, \mathrm{SD}$ and LD+T RA and surround. $\boldsymbol{G}, \boldsymbol{H}$, High-magnification images from boxes of corresponding SD and LD + T RA. I, J, High-magnification images from heavily labeled cells outside of HVC and RA (corresponding boxes in $\boldsymbol{E}$ and $\boldsymbol{B}$ ). BDNF mRNA probe label is brown, slides are counterstained with Cresyl Violet.

$\mathrm{ng} / \mathrm{ml}, p=5.9 \times 10^{-6}, t$ test $t=7.03 ; \mathrm{df}=14 ; \mathrm{CV}$ for intra-assay precision $=0.07)$.

\section{In situ hybridization to assess BDNF expression}

We previously reported an increase in BDNF mRNA in HVC of $\mathrm{LD}+\mathrm{T}$ birds using a radiolabeled riboprobe targeting zebra finch BDNF (Wissman and Brenowitz, 2009). In the present study, we confirmed this result using a riboprobe targeting GWCS BDNF, which shows $94 \%$ sequence identity with zebra finch BDNF.

BDNF mRNA expression varied throughout the forebrain. BDNF mRNA was expressed at lower levels in cells both within and ventral to HVC of both SD and LD+T birds (Fig. $1 A-D$ ). Strong expression was noted in a subset of hippocampal neurons (Fig. 1J). Additionally, we observed strong expression in some 


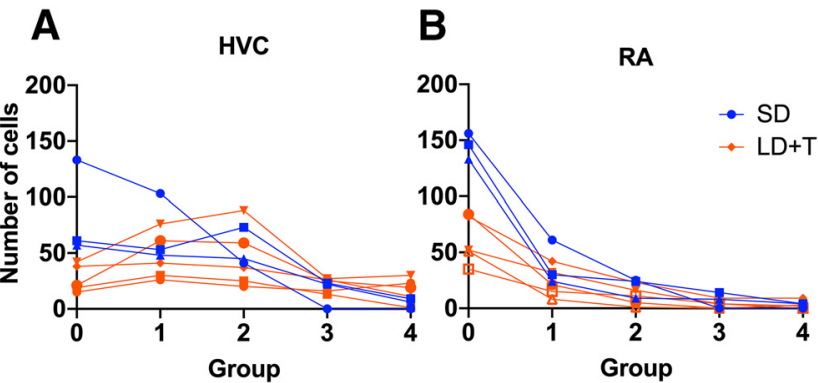

Figure 2. Probe intensity distribution in HVC and RA. $A$, Cells that express BDNF mRNA in HVC increase in LD $+\mathrm{T}$ birds (orange) compared with SD birds (blue). $\boldsymbol{B}, \mathrm{RA}$ expression is minimal. Each symbol represents a different animal. Group refers to dots/cell categories (see Methods).

portions of the rostral-most nidopallium, in the mesopallium and in the hyperpallium (data not shown). Unlike HVC, expression was almost nonexistent within RA of both $\mathrm{SD}$ and $\mathrm{LD}+\mathrm{T}$ birds (Fig. $1 E-H)$ ). Strong expression was observed in a subset of neurons in the surrounding arcopallium, both dorsally and posteriorly (Fig. 1I). We observed weak BDNF mRNA expression in LMAN (data not shown).

In addition, we extended this finding by carrying out a celllevel quantification of labeling. While $\mathrm{LD}+\mathrm{T}$ treatment caused an increase in the proportion of HVC neurons expressing BDNF mRNA, it did not affect the level of expression (Fig. $2 A, B$, orange). In SD birds (Fig. $2 A, B$, blue), $64 \%$ (SEM 6.1\%; $n=3$ ) of HVC cells had detectable BDNF expression, and the proportion rose to $81.1 \%$ (SEM, 3.1\%; $n=5)$ in $\mathrm{LD}+\mathrm{T}$ birds. This represents a significant increase in the proportion of cells expressing BDNF $(p=0.03, t$ test; $t=2.820 ; \mathrm{df}=6)$. The level of BDNF expression in HVC cells did not increase significantly with LD + T treatment. The average expression score in HVC for cells that showed expression was 1.7 (SEM, 0.2) for SD birds and 2.0 (SEM, 0.1) for $\mathrm{LD}+\mathrm{T}$ birds $(p=0.23$, nested $t$ test; $t=1.32, \mathrm{df}=6)$.

In RA of SD birds, BDNF mRNA was detected in 6.0\% (SEM, $0.7 \% ; n=3$ ) of cells (Fig. $2 B$ ). This fraction rose to $29.3 \%$ (SEM, $5.3 \% ; n=5)$ in LD+T birds. This represents a significant increase in the proportion of cells expressing BDNF $(p=0.02, t$ test; $t=3.28$; $\mathrm{df}=6$ ), but the level of expression in these cells remained very low. The average expression score in RA for cells that showed expression was 1.0 (SEM, $0.0 ; n=3$ ) for SD birds and 1.3 (SEM, $0.17 ; n=5$ ) for LD+T birds. This did not represent a significant increase in expression levels $(p=0.12$, nested $t$ test; $t=1.84$, df $=6$ ).

\section{Electrophysiology}

Consistent with previous studies, the mean firing rates of RA neurons in SD birds infused with vehicle $(2.7 \pm 0.77 \mathrm{~Hz} ; n=3$; Fig. $3 A)$ were significantly lower than in $\mathrm{LD}+\mathrm{T}$ birds $(4.7 \pm 0.26$ $\mathrm{Hz} ; n=7$; Fig. $3 B$; nested one-way ANOVA, $F_{(4,17)}=12.05, p<$ 0.0001 ). A post hoc $t$ test (Table 1 ) confirmed that $\mathrm{LD}+\mathrm{T}$ conditions increased the firing rate of RA neurons compared with SD birds $(p=0.0374)$.

Infusion of BDNF into RA of SD birds ( $n=5$, Fig. $3 C)$ increased the mean spontaneous firing rate to $5.3 \pm 0.63 \mathrm{~Hz}, p=$ 0.0196 , post hoc $t$ test comparing SD with SD+BDNF). This was not significantly different from that seen in $\mathrm{LD}+\mathrm{T}$ birds $(p=$ 0.97 , post hoc $t$ test). We infused cytochrome $c(12 \mathrm{kDa})$ near RA in birds maintained on SD conditions as a protein treatment control of similar size to BDNF (mature BDNF, $14 \mathrm{kDa}$ ). Firing rates in RA of cytochrome $c$ infused birds averaged $(3.0 \pm 0.22$ $\mathrm{Hz} ; n=3$ ), which did not differ from those in SD control birds
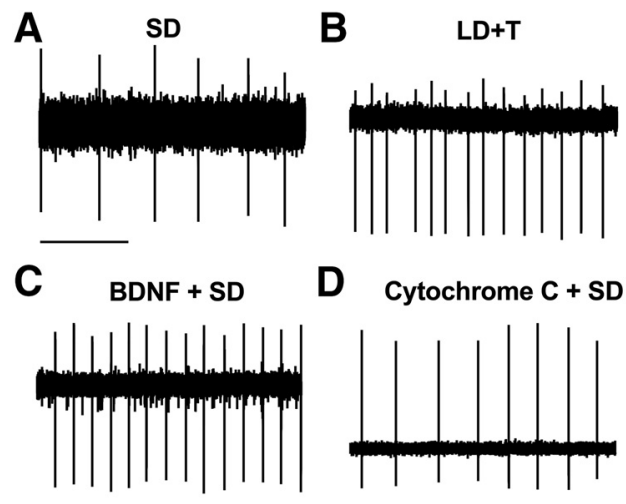

D Cytochrome C + SD

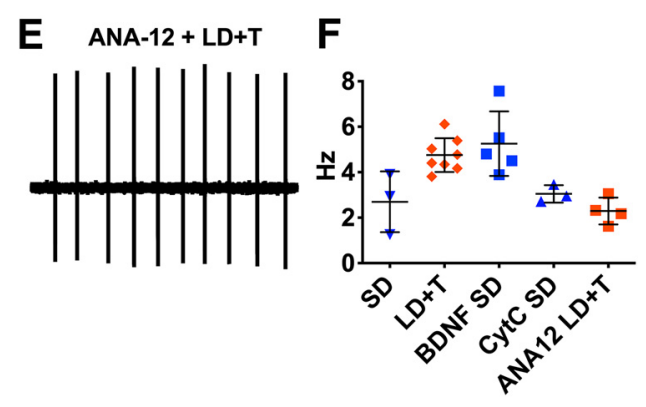

Figure 3. $\boldsymbol{A}-\boldsymbol{E}$, Representative spontaneous firing of neurons in each condition. BDNF infusion increases the RA firing rate similar to the $L D+T$ condition, but CytC (control) did not. ANA12 reduces the firing rate of $L D+T$ birds to that of the SD condition. Calibration: $\boldsymbol{A}$ (applies to all traces), 1 s. $\boldsymbol{F}$, Mean firing rates for all birds in each condition. Birds kept on SD are blue; birds kept on $L D+T$ are orange.

Table 1. Post hoct test results for firing rate analysis

\begin{tabular}{lllr}
\hline $\begin{array}{l}\text { Tukey's } \\
\text { multiple-comparisons test }\end{array}$ & $\begin{array}{l}\text { Mean } \\
\text { difference }(\mathrm{Hz})\end{array}$ & $\begin{array}{l}95 \% \mathrm{Cl} \text { of } \\
\text { difference }(\mathrm{Hz})\end{array}$ & $\begin{array}{l}\text { Adjusted } \\
p \text { value }\end{array}$ \\
\hline BDNF vs ANA12 & 2.799 & $1.253-4.346$ & 0.0003 \\
BDNF vs CytC & 2.164 & $0.4850-3.843$ & 0.0084 \\
BDNF vs SD & 2.090 & $0.2799-3.900$ & 0.0196 \\
BDNF vs LD+T & 0.2989 & -1.208 to 1.806 & 0.9727 \\
ANA12 vs CytC & -0.6355 & -2.242 to 0.9708 & 0.7494 \\
ANA12 vs SD & -0.7093 & -2.452 to 1.034 & 0.7302 \\
ANA12 vs LD + T & -2.501 & -3.926 to -1.075 & 0.0005 \\
CytC vs SD & -0.07387 & -1.935 to 1.788 & $>0.9999$ \\
CytC vs LD + T & -1.865 & -3.434 to -0.2967 & 0.0158 \\
SD vs LD + T & -1.791 & -3.500 to -0.08298 & 0.0374 \\
\hline
\end{tabular}

( $p=0.99$; Fig. $3 D)$ and was less than the firing rate in $\mathrm{LD}+\mathrm{T}$ birds ( $p=0.016$, post hoc $t$ test).

The above results demonstrate that the infusion of BDNF, but not cytochrome $c$, is sufficient to increase the activity of RA. To test whether BDNF action is necessary for RA neurons to fire at a higher rate in $\mathrm{LD}+\mathrm{T}$ birds, we infused the small-molecule TrkB antagonist ANA-12 into RA of $\mathrm{LD}+\mathrm{T}$ birds $(n=4$; Fig. $3 E)$. ANA-12 prevented the increase in RA neuron activity compared with $\mathrm{LD}+\mathrm{T}$ vehicle control birds $(p=0.0005$, post hoc $t$ test; Fig. $3 E, F)$.

\section{Discussion}

From this study, we conclude that BDNF infusion in RA in SD birds is sufficient to increase the spontaneous firing rate of RA neurons, and that $\mathrm{TrkB}$ receptor activation is necessary for these changes to occur in response to $\mathrm{LD}+\mathrm{T}$ treatment. Together, these findings strongly suggest that the transsynaptic trophic effects of HVC on RA neuronal activity are mediated by BDNF acting on TrkB within RA neurons. 
In RA of SD birds, almost no BDNF expression was detected, and in RA of LD $+\mathrm{T}$ birds, only $\sim 30 \%$ of neurons showed any BDNF expression, despite strong expression in the hippocampus and areas surrounding RA. Even in these RA cells, expression was low. Because the infusion of exogenous BDNF in SD birds was sufficient to cause an increase in the firing rate of RA neurons similar to that seen in $\mathrm{LD}+\mathrm{T}$ birds, the critical BDNF acting in RA of LD + T birds likely comes from outside RA. The most likely source is HVC, which lies $\sim 2 \mathrm{~mm}$ away from RA but sends a dense projection and is the primary source of RA innervation. $\mathrm{LD}+\mathrm{T}$ treatment causes upregulation of BDNF in HVC, local infusion of androgen and estrogen into HVC causes changes in RA neuronal size and activity (Meitzen et al., 2007b), and afferent input from HVC is necessary for these changes in RA (Brenowitz and Lent, 2001). Together, these various pieces of evidence point strongly toward HVC as the critical source of BDNF causing the changes in RA.

We did not observe a significant rise in the level of BDNF expression in HVC neurons of LD + T birds, but a greater fraction of HVC neurons showed expression. Combined with the fact that $\mathrm{LD}+\mathrm{T}$ conditions cause an increase in the total number of $\mathrm{HVC}$ neurons (Tramontin et al., 1998), more total BDNF is likely to be produced in HVC and delivered to RA.

RA also receives afferent input from LMAN neurons. In early zebra finch development, lesions of LMAN lead to the death of RA neurons (Akutagawa and Konishi, 1994), suggesting that LMAN can have a trophic influence on RA. In addition, LMAN shows transient expression of BDNF-like immunoreactivity in finches (Akutagawa and Konishi, 1998). RA also receives diffuse neuromodulatory inputs from cholinergic, dopaminergic, serotonergic, and noradrenergic neurons in the basal forebrain, midbrain, and brainstem (Li and Sakaguchi, 1997; Mello et al., 1998; Appeltants et al., 2002; Kubikova et al., 2010; Wood et al., 2011). Nothing is known about BDNF expression in those neuronal populations or whether it changes seasonally. Our previous research shows, however, that HVC is both necessary and sufficient for seasonal changes in RA (Brenowitz and Lent, 2001, 2002; Meitzen et al., 2007b; Brenowitz, 2015). When HVC is lesioned but LMAN is intact, RA activity does not change following LD + T treatment. LMAN or neuromodulatory inputs may thus be permissive for RA changes, but seem not to send the key instructive signal to RA.

The firing rate measure that we have used here serves as a proxy for a variety of morphological and electrophysiological properties of RA neurons that directly contribute to changes in song quality. Soma size grows in association with increased dendritic length and spine density, presumably to accommodate synapses from new axons arriving from HVC or from other RA neurons (Herrmann and Arnold, 1991; Spiro et al., 1999; Sizemore and Perkel, 2008). Spontaneous firing rate is a manifestation of other electrical properties, including increased excitability (Meitzen et al., 2009a), that change how RA neurons respond to activity in their afferents. This increased excitability may be accompanied by synaptic plasticity required for increased song quality in breeding birds. A combination of such changes presumably contributes to the ability of RA neurons to fire highfrequency bursts of action potentials that are aligned with nearly millisecond precision with song (Chi and Margoliash, 2001).

We applied BDNF to RA in a sustained fashion over $14 \mathrm{~d}$. In other studies, brief application (minutes) of BDNF has been reported to cause rapid excitatory effects on cortical pyramidal cells (Kovalchuk et al., 2002). This effect reversed immediately upon washout. Because our slices were bathed in ACSF for 1- $8 \mathrm{~h}$ before recordings, it is unlikely that this transient effect of BDNF underlies the increased firing rate of RA neurons that we observed. Brief application of BDNF has been reported to cause prolonged increases of synaptic strength in hippocampal pyramidal neurons (Kang and Schuman, 1995), but this effect cannot explain our observations on RA neuron spontaneous activity because our experiments were performed in the presence of synaptic blockers and the absence of BDNF in the bathing solution. It is more likely that sustained actions of BDNF over the 2 weeks of treatment caused the effects we observed on RA neuron firing rate (Meitzen et al., 2009b) .

Sustained application of BDNF is also implicated in modulating long-term synaptic plasticity in mammalian hippocampus ( $\mathrm{Ji}$ et al., 2010). While there is evidence of long-term potentiation (Mehaffey and Doupe, 2015) and long-term depression (Sizemore and Perkel, 2011) of synaptic transmission in zebra finch RA, we do not know yet whether BDNF is involved in those processes. Nor do we know whether any synaptic plasticity processes take place in response to BDNF or seasonal modulation in sparrows, though new synapses from HVC neurons onto RA neurons must be generated in LD+T birds (Cohen et al., 2016).

BDNF can act transsynaptically both in the anterograde and retrograde directions (Zhou and Rush, 1996; Altar et al., 1997; Kohara et al., 2001), and has been posited to be a key regulator of synaptic plasticity (Lu et al., 2014; Leal et al., 2017). The song system is unique, however, in that (1) the seasonal changes in electrical properties of RA neurons induced by BDNF are quite dramatic; and (2) the target nucleus (RA) is nearly devoid of BDNF and appears to be entirely dependent upon transsynaptic BDNF to successfully enter breeding conditions. This is particularly remarkable given that presynaptic neurons supplying BDNF are a significant distance $(\sim 2 \mathrm{~mm})$ from the target.

Overall, our findings identify BDNF as the signal arising from HVC that acts transsynaptically in RA to cause changes in electrophysiological properties of neurons. This role of BDNF is a key part of the regeneration of a neural circuit at the beginning of the breeding condition and represents one element of a concerted growth effect triggered by sex steroids. The regenerated circuit supports a critical communication behavior that is important for reproduction. Harnessing this process could have potential therapeutic applications, for example after stroke, neurodegeneration, or traumatic brain injury.

\section{References}

Akutagawa E, Konishi M (1994) Two separate areas of the brain differentially guide the development of a song control nucleus in the zebra finch. Proc Natl Acad Sci U S A 91:12413-12417.

Akutagawa E, Konishi M (1998) Transient expression and transport of brain-derived neurotrophic factor in the male zebra finch's song system during vocal development. Proc Natl Acad Sci U S A 95:11429-11434.

Altar CA, Cai N, Bliven T, Juhasz M, Conner JM, Acheson AL, Lindsay RM, Wiegand SJ (1997) Anterograde transport of brain-derived neurotrophic factor and its role in the brain. Nature 389:856-860.

Appeltants D, Ball GF, Balthazart J (2002) The origin of catecholaminergic inputs to the song control nucleus RA in canaries. Neuroreport 13:649653.

Béjot Y, Prigent-Tessier A, Cachia C, Giroud M, Mossiat C, Bertrand N, Garnier P, Marie C (2011) Time-dependent contribution of non neuronal cells to BDNF production after ischemic stroke in rats. Neurochem Int 58:102-111.

Brenowitz EA (2008) Plasticity of the song control system in adult birds. In: Neuroscience of birdsong (Zeigler HP, Marler P, eds), pp 332-349. Cambridge: Cambridge UP.

Brenowitz EA (2013) Testosterone and brain-derived neurotrophic factor interactions in the avian song control system. Neuroscience 239:115-123. 
Brenowitz EA (2015) Transsynaptic trophic effects of steroid hormones in an avian model of adult brain plasticity. Front Neuroendocrinol 37:119-128.

Brenowitz EA, Lent K (2001) Afferent input is necessary for seasonal growth and maintenance of adult avian song control circuits. J Neurosci 21:2320-2329.

Brenowitz EA, Lent K (2002) Act locally and think globally: intracerebral testosterone implants induce seasonal-like growth of adult avian song control circuits. Proc Natl Acad Sci U S A 99:12421-12426.

Cazorla M, Prémont J, Mann A, Girard N, Kellendonk C, Rognan D (2011) Identification of a low-molecular weight TrkB antagonist with anxiolytic and antidepressant activity in mice. J Clin Invest 121:1846-1857.

Chen A, Xiong LJ, Tong Y, Mao M (2013) Neuroprotective effect of brainderived neurotrophic factor mediated by autophagy through the PI3K/ Akt/mTOR pathway. Mol Med Rep 8:1011-1016.

Chi Z, Margoliash D (2001) Temporal precision and temporal drift in brain and behavior of zebra finch song. Neuron 32:899-910.

Cohen RE, Macedo-Lima M, Miller KE, Brenowitz EA (2016) Adult neurogenesis leads to the functional reconstruction of a telencephalic neural circuit. J Neurosci 36:8947-8956.

Conner JM, Lauterborn JC, Yan Q, Gall CM, Varon S (1997) Distribution of brain-derived neurotrophic factor (BDNF) protein and mRNA in the normal adult rat CNS: evidence for anterograde axonal transport. J Neurosci 17:2295-2313.

Detre S, Saclani Jotti G, Dowsett M (1995) A "quickscore" method for immunohistochemical semiquantitation: validation for oestrogen receptor in breast carcinomas. J Clin Pathol 48:876-878.

Dittrich F, Feng Y, Metzdorf R, Gahr M (1999) Estrogen-inducible, sexspecific expression of brain-derived neurotrophic factor mRNA in a forebrain song control nucleus of the juvenile zebra finch. Proc Natl Acad Sci U S A 96:8241-8246.

Galuske RA, Kim DS, Castrén E, Singer W (2000) Differential effects of neurotrophins on ocular dominance plasticity in developing and adult cat visual cortex. Eur J Neurosci 12:3315-3330.

Guo W, Nagappan G, Lu B (2018) Differential effects of transient and sustained activation of BDNF-TrkB signaling. Dev Neurobiol 78:647-659.

Herrmann K, Arnold AP (1991) The development of afferent projections to the robust archistriatal nucleus in male zebra finches: a quantitative electron microscopic study. J Neurosci 11:2063-2074.

Jean YY, Lercher LD, Dreyfus CF (2008) Glutamate elicits release of BDNF from basal forebrain astrocytes in a process dependent on metabotropic receptors and the PLC pathway. Neuron Glia Biol 4:35-42.

Ji Y, Lu Y, Yang F, Shen W, Tang TT, Feng L, Duan S, Lu B (2010) Acute and gradual increases in BDNF concentration elicit distinct signaling and functions in neurons. Nat Neurosci 13:302-309.

Johnson F, Hohmann SE, DiStefano PS, Bottjer SW (1997) Neurotrophins suppress apoptosis induced by deafferentation of an avian motor-cortical region. J Neurosci 17:2101-2111.

Kang HJ, Schuman EM (1995) Neurotrophin-induced modulation of synaptic transmission in the adult hippocampus. J Physiol Paris 89:11-22.

Kirn JR, DeVoogd TJ (1989) Genesis and death of vocal control neurons during sexual differentiation in the zebra finch. J Neurosci 9:3176-3187.

Kohara K, Kitamura A, Morishima M, Tsumoto T (2001) Activitydependent transfer of brain-derived neurotrophic factor to postsynaptic neurons. Science 291:2419-2423.

Kohara K, Kitamura A, Adachi N, Nishida M, Itami C, Nakamura S, Tsumoto T (2003) Inhibitory but not excitatory cortical neurons require presynaptic brain-derived neurotrophic factor for dendritic development, as revealed by chimera cell culture. J Neurosci 23:6123-6131.

Kovalchuk Y, Hanse E, Kafitz KW, Konnerth A (2002) Postsynaptic induction of BDNF-mediated long-term potentiation. Science 295:1729-1734.

Kowiański P, Lietzau G, Czuba E, Waśkow M, Steliga A, Moryś J (2018) BDNF: a key factor with multipotent impact on brain signaling and synaptic plasticity. Cell Mol Neurobiol 38:579-593.

Kubikova L, Wada K, Jarvis ED (2010) Dopamine receptors in a songbird brain. J Comp Neurol 518:741-769.

Leal G, Comprido D, Duarte CB (2014) BDNF-induced local protein synthesis and synaptic plasticity. Neuropharmacology 76:639-656.

Leal G, Bramham CR, Duarte CB (2017) BDNF and hippocampal synaptic plasticity. Vitam Horm 104:153-195.
Li R, Sakaguchi H (1997) Cholinergic innervation of the song control nuclei by the ventral paleostriatum in the zebra finch: a double-labeling study with retrograde fluorescent tracers and choline acetyltransferase immunohistochemistry. Brain Res 763:239-246.

Lu B, Nagappan G, Lu Y (2014) BDNF and synaptic plasticity, cognitive function, and dysfunction. Handb Exp Pharmacol 220:223-250.

Mehaffey WH, Doupe AJ (2015) Naturalistic stimulation drives opposing heterosynaptic plasticity at two inputs to songbird cortex. Nat Neurosci 18:1272-1280.

Meitzen J, Perkel DJ, Brenowitz EA (2007a) Seasonal changes in intrinsic electrophysiological activity of song control neurons in wild song sparrows. J Comp Physiol A Neuroethol Sens Neural Behav Physiol 193:677-683.

Meitzen J, Moore IT, Lent K, Brenowitz EA, Perkel DJ (2007b) Steroid hormones act transsynaptically within the forebrain to regulate neuronal phenotype and song stereotypy. J Neurosci 27:12045-12057.

Meitzen J, Weaver AL, Brenowitz EA, Perkel DJ (2009a) Plastic and stable electrophysiological properties of adult avian forebrain song-control neurons across changing breeding conditions. J Neurosci 29:6558-6567.

Meitzen J, Thompson CK, Choi H, Perkel DJ, Brenowitz EA (2009b) Time course of changes in Gambel's white-crowned sparrow song behavior following transitions in breeding condition. Horm Behav 55:217-227.

Mello CV, Pinaud R, Ribeiro S (1998) Noradrenergic system of the zebra finch brain: immunocytochemical study of dopamine-beta-hydroxylase. J Comp Neurol 400:207-228.

Nottebohm F, Nottebohm ME, Crane LA, Wingfield JC (1987) Seasonal changes in gonadal hormone levels of adult male canaries and their relation to song. Behav Neural Biol 47:197-211.

Park KH, Meitzen J, Moore IT, Brenowitz EA, Perkel DJ (2005) Seasonallike plasticity of spontaneous firing rate in a songbird pre-motor nucleus. J Neurobiol 64:181-191.

Schneider CA, Rasband WS, Eliceiri KW (2012) NIH image to ImageJ: 25 years of image analysis. Nat Methods 9:671-675.

Sizemore M, Perkel DJ (2008) Noradrenergic and GABA B receptor activation differentially modulate inputs to the premotor nucleus RA in zebra finches. J Neurophysiol 100:8-18.

Sizemore M, Perkel DJ (2011) Premotor synaptic plasticity limited to the critical period for song learning. Proc Natl Acad Sci U S A 108:17492-17497.

Smith GT, Brenowitz EA, Wingfield JC, Baptista LF (1995) Seasonal changes in song nuclei and song behavior in Gambel's white-crowned sparrows. J Neurobiol 28:114-125.

Spiro JE, Dalva MB, Mooney R (1999) Long-range inhibition within the zebra finch song nucleus RA can coordinate the firing of multiple projection neurons. J Neurophysiol 81:3007-3020.

Tang YP, Wade J (2016) Sex and age differences in brain-derived neurotrophic factor and vimentin in the zebra finch song system: relationships to newly generated cells. J Comp Neurol 524:1081-1096.

Thompson CK, Meitzen J, Replogle K, Drnevich J, Lent KL, Wissman AM, Farin FM, Bammler TK, Beyer RP, Clayton DF, Perkel DJ, Brenowitz EA (2012) Seasonal changes in patterns of gene expression in avian song control brain regions. PLoS One 7:e35119.

Tramontin AD, Smith GT, Breuner CW, Brenowitz EA (1998) Seasonal plasticity and sexual dimorphism in the avian song control system: stereological measurement of neuron density and number. J Comp Neurol 396:186-192.

Tramontin AD, Hartman VN, Brenowitz EA (2000) Breeding conditions induce rapid and sequential growth in adult avian song control circuits: a model of seasonal plasticity in the brain. J Neurosci 20:854-861.

Tropea D, Caleo M, Maffei L (2003) Synergistic effects of brain-derived neurotrophic factor and chondroitinase $\mathrm{ABC}$ on retinal fiber sprouting after denervation of the superior colliculus in adult rats. J Neurosci 23:7034-7044.

Wissman AM, Brenowitz EA (2009) The role of neurotrophins in the seasonallike growth of the avian song control system. J Neurosci 29:6461-6471.

Wood WE, Lovell PV, Mello CV, Perkel DJ (2011) Serotonin, via HTR2 receptors, excites neurons in a cortical-like premotor nucleus necessary for song learning and production. J Neurosci 31:13808-13815.

Zhou XF, Rush RA (1996) Endogenous brain-derived neurotrophic factor is anterogradely transported in primary sensory neurons. Neuroscience 74: 945-953. 